\title{
A New Quantitative Classification of Diabetic Nephropathy by Morphometric Analysis
}

\author{
Masao Kanauchi Kyoko Kitauchi Toshio Hashimoto \\ First Department of Internal Medicine, Nara Medical University, Nara, J apan
}

Dear Sir,

The pathological stage of diabetic nephropathy had been traditionally evaluated using Gellman's criteria [1], on the basis of 4 grades according to the severity of diffuse glomerular lesions. It is generally accepted that the histopathological staging ensures the reliable diagnostic criterion of diabetic nephropathy. However, a wide discrepancy remains among pathologists as to on which basis they discriminate the degree of mesangial area expansion. Therefore, a new quantitative classification of diabetic nephropathy is needed. We attempted to clarify a new histopathological staging of diabetic nephropathy using 30 patients with type 2 diabetes mellitus who underwent renal biopsy (19 males and 11 females, serum creatinine concentrations $0.3-1.8 \mathrm{mg} / \mathrm{dl}$ ). Tissue specimens obtained by percutaneous renal biopsy were processed for morphometric evaluation by light microscopy. Serial sections $3 \mu \mathrm{m}$ thick were cut and stained with periodic acid Schiff. The severity of diffuse glomerular changes was graded on a scale of D1 through D4 according to Gellman's criteria [1] by a single consultant pathologist as follows: D1 (local lesion present within each glomerulus and focal lesion present within the kidney); D2 (mesangial thickening is diffuse within the glomerulus and generalized throughout the kidney); D3 (capillary lumina are narrowed and obliterated only locally); and D4 (the lumen is generally narrowed and the entire glomerulus is ischemic and appears to be hyalinized). The severity of glomerular lesions was also estimated by quantitative morphometric studies [2]. Briefly, PASstained specimens were analyzed using a color image processor (SPICCA-II, Olympus Co., Tokyo, Japan) measuring glomerular area (GA) and mesangial area (MA). The GA was defined as inner area of glomerular tuft outline, and the mesangial rate (MR\%) was defined as the ratio of MA to GA.

The mean value of MR\% was $14.4 \pm$ $2.1 \%$ in $\mathrm{D} 1,19.7 \pm 3.0 \%$ in $\mathrm{D} 2,25.3 \pm$ $2.3 \%$ in $\mathrm{D} 3$, and $35.2 \pm 2.5 \%$ in $\mathrm{D} 4$. There

\section{KARGER}

Fax +4161306 1234 E-Mail karger@karger.ch www.karger.com
(C) 2002 S. Karger AG, Basel 0028-2766/02/0924-0955\$18.50/0

Accessible online at: www.karger.com/journals/nef
Dr. Masao Kanauchi

First Department of Internal Medicine, Nara Medical University

840, Shijo-cho, Kashihara City, Nara 634-0813 (Japan)

Tel. +81 74422 3051, Fax +81 74428 1880, E-Mail kanauchi@nmu-gw.naramed-u.ac.jp 
was a significant correlation between MR $\%$ and the grade of diffuse lesions (D) assessed by Gellman's criteria $(\mathrm{MR} \%=6.65 \times \mathrm{D}+$ $7.05, r=0.939, p<0.0001$ ) (fig. 1). Stages of diabetic nephropathy were classifiable into four classes by the discriminating analysis. Class 1 proved to comprise 10 cases with their MR\% under 16.9\%; class 2, 10 cases with their MR \% between 17.0 and $23.6 \%$; class 3, 5 cases with their MR $\%$ between 23.7 and $30.2 \%$, and class 4,5 cases with their MR\% over $30.3 \%$. Urinary albumin excretion rate $(62 \pm 12 \mathrm{mg} / 24 \mathrm{~h}, 435 \pm 195$, $3,175 \pm 1,147$, and 5,605 $\pm 2,560$, respectively) and creatinine clearance (108 \pm 26 $\mathrm{ml} / \mathrm{min}, 96 \pm 36,63 \pm 30$, and $50 \pm 16$, respectively) significantly differed among the four groups.
In the pioneer paper in the field of renal pathology in diabetic nephropathy by Gellman et al. [1], it had been previously used for evaluating the severity of diffuse glomerular lesions. However, diagnosis according to this criteria is quite prone to remarkable interobserver variation. In later years, morphometric analysis using the stereologic techniques of electron microscopy have been widely investigated in diabetic nephropathy [3-5]. The stereologic technique of electron microscopy is an exacting but time consuming procedure, whereas the computer-assisted quantitative morphometric analysis used in our study is processed to obtain a similar precise evaluation. It could provide a valid routine investigation with advantageous clinical implications.

\section{References}

1 Gellman DD, Pirani CL, Soothill JF, Muehrcke RC, Kark RM: Diabetic nephropathy: A clinical and pathologic study based on renal biopsies. Medicine 1959;38:312-367.

2 Nishimoto K, Shiiki H, Nishino T, Kimura T, Sasaki Y, Yamasaki M, Morikawa H, Fujimoto S, Dohi K: Glomerular hypertrophy in preeclamptic patients with focal segmental glomerulosclerosis. Clin Nephrol 1999;51:209219.

3 Hayashi H, Karasawa R, Inn H, Saitou T, Ueno M, Nishi S, Suzuki Y, Ogino S, Maruyama Y, Kouda Y, Arakawa M: An electron microscopic study of glomeruli in Japanese patients with non-insulin dependent diabetes mellitus. Kidney Int 1992;41:749-757.

4 Osterby R, Gall MA, Schmitz A, Nielsen FS, Nyberg G, Parving HH: Glomerular structure and function in proteinuric type 2 diabetic patients. Diabetologia 1993;36:1064-1070.

5 White KE, Bilous RW: Type 2 diabetic patients with nephropathy show structural-functional relationships that are similar to type 1 disease. J Am Soc Nephrol 2000;11:1667-1673. 